\title{
Psychiatry in Mauritius
}

\author{
D. R. Greedharry, Department of Psychological Medicine, Ely Hospital, Cardiff
}

Mauritius is a 720 sq mile island situated in the Indian Occan. It has a population of about a million. made up of various racial backgrounds: Indian, African, European and Chinese. Those of Indian descent belong to the Hindu and Muslim faiths; those of African and European descent belong to the Roman Catholic faith (by and large), as do most of the people of Chinese origin. The economy rests on the export of sugar and tobacco, making the country an agricultural one. Diversification of the economy is under way.

The medical services are free, but private practice plays a large part in meeting the needs of the people. There is only one big institution for mentally ill patients, named after Brown Sequard (the illustrious neurologist born in Mauritius). The institution was opened more than a century ago in 1879 to accommodate 260 patients. Today the hospital has around 900 beds.

The medical staff at Brown Sequard is made up of two consultants, two senior specialists and two registrar specialists. These are all promotional posts like the Civil Service. The orientation of the psychiatrists differs significantly as they have had their psychiatric training in the UK. France and India. Some trainecs are now going to Sri Lanka and East European countrics.

In the hospital the approach is multidisciplinary, but there are no organized social services to provide community support. This may be, perhaps, because of the extended family system that operates. There is an occupational therapy department with a full-time therapist. There is no clinical psychologist attached to the hospital-but there are three clinical psychologists in the island-two of them working privately and the third one working for the Roman Catholic church, concentrating more on marital or sexual problems arising in a marital context. The other two psychologists offer both bchavioural and psychotherapeutic treatment. ECT is used regularly, but there is no trained anaesthetist attending. Instead. the administering doctor gives the patient a shortacting anaesthetic. Drugs are used as in the West. Depot injections are also available, but they are very expensive. The medical staff of the hospital also carry out the bulk of private practice. There is no division into sub-specialties, although there is a school for mentally impaired children. The practice of psychiatry has to be necessarily medically orientated. I believe these two features to be very relevant to the training of psychiatrists committed to working in developing countries. Compulsory admission to the hospital is via the magistrate's court, on a medical recommendation.

Patients exhibit a tremendous amount of somatization and therefore a good clinical background is essential for the proper diagnosis and management. Hair-loss, for example, is associated with depression. Facilities for investigations are limited. The hospital provides EEG facilities; there are no facilities for lithium estimation or thyroid function teststhese are sent to private laboratories in the UK. There is a high degree of polypharmacy which suggests that the treatment is mainly symptomatic and not holistic.

In spite of these limitations, the WHO Technical Report No 381 (published in 1968) recommended that Mauritius was the most suitable location for (a) 'the study of critical periods of development to examine the effect of environmental factors on subsequent mental health and (b) longitudinal neurophysiological studies of high risk subjects."

Mauritius is unique in the sense that, although it belongs to Africa geographically, its multi-cultural population is not made up of any tribes. However, people resort to the services of 'black magicians' to a significant extent. Apart from the neuroses and psychoses that transcend geographical and cultural barriers, drug addiction constitutes up to 40 per cent of hospital admissions. In private practice, any effort at some form of psychotherapy for the addicts is very unrewarding. Patients are deterred by the cost. In contrast, free psychotherapy offered by the Catholic Church for marital problems seems to be quite effective.

There is no doubt that the psychiatrist for the developing countries needs a broad-based training with emphasis on neurology and neuropsychiatry.

REFERENCE

ISerban. S. (Ed.) (1978) Cognitive Defects in the Development of Menial Illness. New York: Bruner/Mazel. 